\title{
Editorials
}

\section{Hepatitis B immunisation in Britain: time to change?}

\author{
The increasing prevalence of chronic infection, mainly due to immigration from endemic areas, \\ may warrant universal immunisation
}

$\mathrm{T}$ The World Health Organization recommended that, by 1997, all countries should introduce a programme of universal immunisation against hepatitis B at birth, in infancy, or in adolescence, according to endemicity. ${ }^{1}$ By the end of 2005, 168 countries worldwide and 44 of 52 countries in WHO's European region had implemented this. The United Kingdom continues to implement a selective immunisation programme for hepatitis B, targeting high risk groups and screening all women attending antenatal clinics so that the babies of any infected mothers can be immunised at birth. This approach has come in for some criticism, not only internationally but also within the UK. ${ }^{2}$ Should the UK now adopt universal immunisation against hepatitis $\mathrm{B}$ ?

In contrast with other European countries, particularly in southern Europe, the UK has one of the lowest incidences of hepatitis B infection worldwide, ${ }^{3}$ but has about 180000 people with chronic hepatitis B infection. ${ }^{4}$ The Netherlands and the Nordic countries, none of which have introduced universal immunisation, also have low rates. ${ }^{5}$ Is the British selective programme effective?

An important factor in recommending universal screening of pregnant women in the UK was the finding that selective programmes failed to identify $50 \%$ of those with hepatitis B infection. ${ }^{6}$ A recent analysis of laboratory reports by the Health Protection Agency in England and Wales highlighted injecting drug use as the most common route by which this infection is acquired, followed by men having sex with men, and then by heterosexual transmission. More than 250 cases of new chronic infections arise annually in England and Wales ${ }^{3}$ and are potentially preventable by the UK's current vaccination programme aimed at high risk groups if they are reached before exposure.

The Health Protection Agency estimated that only 44\% of infections are potentially preventable by the programme of selective immunisation in England and Wales; preventive measures should precede exposure to risk. Of particular importance is the average net immigration of about 6500 people with chronic hepatitis B infection each year between 1996 and 2000. ${ }^{3}$ The total is cumulative, and therefore the pool is increasing. These cases could not be prevented by vaccination programmes within England and Wales, but people with chronic infection can spread infection perinatally, horizontally, and sexually. During the past two years one London hepatology clinic has reported almost 2000 cases of hepatitis B infection, mostly among people who were not born in the UK; cases occurred in newly referred patients as well as those seen at annual follow up visits (H C Thomas, personal communication). Medical percutaneous procedures done overseas, particularly in the Indian subcontinent, were also a risk factor. Holidays by sexually active young people to southern European resorts may also increase the risk of this infection.

Cultural mores may confine infection within immigrant communities for a while. But horizontal transmission of hepatitis $\mathrm{B}$ infection has been reported among Somali immigrants at an early age, ${ }^{7}$ and infected children might spread infection beyond their own communities-for example, in nurseries, day care centres, and at school. In Ireland the incidence of hepatitis B infection increased markedly between 1997 and 2003, in part reflecting migration from countries with high rates of infection. Consequently, Irish public health services are considering a universal immunisation programme (B Keogh, personal communication).

Hepatitis B vaccination is already recommended in the Netherlands for children with at least one parent born in a country where infection is endemic. ${ }^{5}$ Targeting vaccination at immigrants could be seen as stigmatising and divisive, however, and reaching their children might be difficult. As population movements increase, control of infectious diseases must be supported by regional and global strategies.

In several countries in western Europe the infant immunisation programme now uses a hexavalent vaccine that includes hepatitis B vaccine. Accumulated data from several studies indicate that hepatitis $\mathrm{B}$ vaccines given in infancy induce long term protection: even though antibody levels may decline, immunological memory persists. ${ }^{8}$ Such vaccines may be costly but are much easier to deliver than universal vaccine programmes run separately for different infections.

One barrier to combined universal immunisation in infancy would be the unfounded anxiety some people feel about giving multiple antigens to babies. Furthermore, immune responses and clinical protection against Haemophilus influenzae type b is reduced in some combination vaccines, and British authorities want to ensure that any combined vaccine would not jeopardise control of other infections. ${ }^{9}$ A two dose (rather than three dose) schedule of hepatitis B vaccine could be given in adolescence instead. This schedule has been shown to be acceptable and effective in a deprived area of Glasgow and in the United States. ${ }^{10} 11$

Would universal vaccination against hepatitis B in the United Kingdom be too costly? This topic was discussed recently at a meeting of the Viral Hepatitis Prevention Board in Edinburgh. ${ }^{12}$ Health economics evaluations in countries with low endemicity have produced variable results, but most were done before vaccine prices were influenced by global markets. Vaccine costs, together with the burden of infection, are the most influential national measures in such economic evaluations. ${ }^{13}$ But the full economic burden of hepatitis B still needs to be established, including the direct costs of providing current and anticipated antiviral treatments for infection and of managing chronic liver disease and hepatocellular carcinoma, as well as the economic and personal costs of early deaths among carriers. If direct costs can be reduced by negotiated tendering, there can no longer be a financial argument against adopting a universal immunisation strategy against hepatitis B in the United Kingdom.

Competing interests: PVD has been principal investigator of vaccine trials for several vaccine manufacturers, for which the University of Antwerp receives research grants. 
1 WHO Expanded Programme on Immunisation, Global Advisory Group. Wkly Epidemiol Rec 1992;3:11-6.

2 Beeching NJ. Hepatitis B infections: universal immunisation should be preferred in Britain. BMJ 2004;329:1059-60.

3 Hahné S, Ramsay M, Balogun K, Edmunds WJ, Mortimer P. Incidence and routes of transmission of hepatitis B virus in England and Wales, 1995-2000: implications for immunisation policy.J Clinical Virol 2004;29:211-20.

4 Department of Health. Getting ahead of the curve. A strategy for combating infectious diseases (including other aspects of health protection). London: $\mathrm{DoH}, 2002$.

5 Van Damme P, Van Herck K. Leuridan E. Vorsters A. Introducing universal hepatitis B vaccination in Europe: differences still remain between countries. 2004 www.eurosurveillance.org/ew/2004/041118.asp (accessed 2 Mar 2006).

6 Chrystie I, Sumner D, Palmer S, Kenney A, Banatvala J. Screening of pregnant women for evidence of current hepatitis B infection: selective or universal? Health Trends 1992;24:1.

7 Aweis D, Brabin BJ, Beeching NJ, Bunn JEG, Cooper C, Gardner K, et al. Hepatitis B prevalence and risk factors for HBsAg carriage amongst Somali households in Liverpool. Commun Dis Public Health 2001;4:240-5.

8 Banatvala JE, Van Damme P. Hepatitis B vaccine- - do we need boosters? J Viral Hepatitis $2003 ; 10: 1-6$

9 McVernon J, Andres N, Slack MP, Ramsay ME. Risk of vaccine failure after haemophilus influenzae type b (Hib) combination vaccines with acellular pertussis. Lancet 2003;361:1521-3.
10 Wallace LA, Bramley JC, Ahmed S, Duff R, Hutchinson SJ, Carman WF, et al. Determinants of universal adolescent hepatitis B vaccine uptake. Arch Dis Child 2004;89:1041-2.

11 Cassidy WM, Watson B, Ioli VA, Williams K, Bird S, West DJ A randomized trial of alternative two and three dose hepatitis B vaccination regimens in adolescent: antibody responses, safety and immunologic memory. Paediatrics 2001;4:626-31.

12 Viral Hepatitis Prevention Board. Can the United Kingdom control viral hepatitis. VHPB meeting, Edinburgh, Nov 2005. www.vhpb.org (accessed 31 Jan 2006).

13 Beutels P. Economic evaluations of hepatitis B immunizations: a global review of recent studies (1994-2000). Health Econ 2001;10:751-74.

doi $10.1136 / \mathrm{bmj} .38797 .621516 .47$

King's College London School of Medicine, St Thomas's Campus, London SE1 $7 \mathrm{EH}$

Jangu Banatvala emeritus professor of clinical virology (jangu@btopenworld.com)

WHO Collaborating Centre for Control and Prevention of Viral Hepatitis,

University of Antwerp, Belgium

Pierre Van Damme director

Vaccine Preventable Diseases and Immunization, WHO Regional Office for Europe, Copenhagen, Denmark

Nedret Emiroglu adviser 